\title{
Experimental Study on Compressive Strength of Manufactured Sand Concrete
}

\author{
Sheng-Dong $\mathrm{HE}^{1, \mathrm{a},{ }^{*} \text {, Hua WANG }}{ }^{2, \mathrm{~b}}$, Lei LI ${ }^{3, \mathrm{c}}$ \\ ${ }^{1,3}$ School of Civil Engineering, Zhengzhou Institute of Aeronautical Industry Management, \\ Zhengzhou, 450002, Henan, China \\ ${ }^{2}$ Highway Engineering Management Department, Xinjiang Vocational and Technical College of \\ Communications, Urumqi, 450002, Xinjiang, China \\ a517253882@qq.com, b1143265580@qq.com, 363801588@qq.com \\ ${ }^{*}$ Corresponding author
}

Keywords: Manufactured Sand, Concrete, Replacement Ratios, Compressive Strength.

\begin{abstract}
Compressive strength is one of the important mechanical properties of conerete, and the indicator of compressive strength of manufactured sand concrete is more important to be promoted. This paper presents the results of the compressive strength tests on concrete specimens using the manufactured sand, the replacement ratios of manufactured sand by mass to the natural sand are 0 , $30 \%, 50 \%, 70 \%$ and $100 \%$ respectively. The optimum replacement ratio the concrete is suggested. This could be used as a reference for the applications of the concrete using the manufactured sand in engineering.
\end{abstract}

\section{Introduction}

As the infrastructure has developed rapidly, but the resources of natural sand is lacking and unsustainable not to meet production requirements. Manufactured sand is broken by rocks or tailings, which could be used in the mixture of cement concrete as fine aggregate instead of natural sand. The use of manufactured sand in concrete structure has become more and more important. It can make construction industry develop with environmentally friendliness and sustainability.

Currently, research on compressive strength of manufactured sand concrete under the main emphasis of a single replacement ratio at $7 \mathrm{~d}$ and $28 \mathrm{~d}$. Xi $\mathrm{Li}[1]$ found the compressive strength of manufactured sand concrete was greater than that of natural sand concrete at the same water cement ratio. Guojian Yang[2] found that the compressive strength growth pattern of manufactured sand concrete and natural sand concrete was similar through comparative study the compressive strength of manufactured sand concrete and natural sand concrete under C15, C20 and C25. Jianbo Zhang[3] found that the development of compressive strength of manufactured sand concrete and natural sand concrete is consistent under C15, C30 and C50. Dong Zhang[4] found the 28d compressive strength of manufactured sand concrete was slightly higher than that of natural sand concrete. Wen Yi[5] found the $7 \mathrm{~d}$ and $28 \mathrm{~d}$ compressive strength of manufactured sand concrete was slightly lower than that of natural sand concrete, but the difference was small under C50. There are also some studies of the compressive strength about manufactured sand concrete under different replacement ratios. Such as, Juanhong Liu[6]found the compressive strength of manufactured sand concrete increased rapidly, and when replacement rate of manufactured sand was $50 \%$, it had a good performance and the compressive strength of $28 \mathrm{~d}$ was highest. Xia Li[7]found when replacement rate of manufactured sand was 60\%, it had a good performance and the compressive strength was highest.

In order to deep study the performances of manufactured sand concrete and expand its field of use, this paper would study mainly the compressive strength of the concrete under case of natural sand substituted by manufactured sand at replacement ratios of $0,30 \%, 50 \%, 70 \%$ and $100 \%$ respectively in C50.

\section{Materials and Their Performance}

\section{Materials}

Cement: P.O 42.5, Henan Mengdian Cement Co., Ltd. 
Coarse aggregate: made by lime stone in Xinmi ,Henan Province; grain sizes were between $10 \mathrm{~mm}$ and $30 \mathrm{~mm}$.

Fine-grained aggregate: two kinds of fine aggregate were used in this test. One was natural sand from Lushan, Henan Province, the other was manufactured sand made in Jiayu, Henan Province.

Fly ash: fly ash I , made by Shouyangshan Thermal Power Plant, Luoyang.

Water-reduce admixtures: TH-2 efficient retardation and water-reduce admixtures.

The performances of raw materials are in line with appropriate standards, norms after testing.

\section{The Main Physical Properties and the Particle Grading of the Manufactured Sand}

The main physical properties and the particle grading of the manufactured sand are described in Table 1 and Table 2 respectively.

Tab. 1 Physical properties of the manufactured sand

\begin{tabular}{lrrrrcc}
\hline $\begin{array}{c}\text { Apparent } \\
\text { density } \\
\left(\mathrm{kg} / \mathrm{m}^{3}\right)\end{array}$ & $\begin{array}{c}\text { Bulk } \\
\text { density } \\
\left(\mathrm{kg} / \mathrm{m}^{3}\right)\end{array}$ & $\begin{array}{c}\text { Moisture } \\
\text { ratio(\%) }\end{array}$ & $\begin{array}{c}\text { Close } \\
\text { void } \\
\text { ratio }(\%)\end{array}$ & $\begin{array}{c}\text { Stone dust } \\
\text { content }(\%)\end{array}$ & $\begin{array}{c}\text { Mud } \\
\text { content }(\%)\end{array}$ & $\begin{array}{c}\text { Fineness } \\
\text { modules }\end{array}$ \\
\hline 2690 & 2380 & 1.7 & 32 & 4.3 & 0 & 3.0 \\
\hline
\end{tabular}

Tab. 2 Particle grading of the manufactured sand

\begin{tabular}{llllllll}
\hline Sieve size (mm) & 9.5 & 4.75 & 2.36 & 1.18 & 0.60 & 0.30 & $\mathbf{0 . 1 5}$ \\
\hline Screen tailings (\%) & 0 & 0.3 & 27.5 & 57.8 & 78.1 & 89.3 & 95 \\
\hline
\end{tabular}

\section{Mix Design of Manufactured Sand and Concrete}

In order to study the mechanical properties of manufactured sand concrete and explore it's application field, C50 was selected as research object. The fundamental mechanical properties of the concrete using the different replacement ratio of manufactured sand by mass was analyzed and discussed. By testing and actual using of concrete, the optimum mix of natural sand concrete was designed. Based on the mix, the mix of manufactured sand concrete by the different replacement ratios was designed. The replacement ratios of manufactured sand by mass to the natural sand are 0 , $0.30,0.50,0.70$ and 1.00 respectively. The mixture ratio of manufactured sand concrete was concluded in Table 5.

Tab. 3 The Mixture ratio of manufactured sand concrete

\begin{tabular}{cccccccc}
\hline $\begin{array}{c}\text { Replacement } \\
\text { Ratios }(\%)\end{array}$ & $\begin{array}{c}\text { Cement } \\
\left(\mathrm{Kg} / \mathrm{m}^{3}\right)\end{array}$ & $\begin{array}{c}\text { Crushed } \\
\text { stone } \\
\left(\mathrm{Kg} / \mathrm{m}^{3}\right)\end{array}$ & $\begin{array}{c}\text { Natural } \\
\text { Sand } \\
\left(\mathrm{Kg} / \mathrm{m}^{3}\right)\end{array}$ & $\begin{array}{c}\text { Manufactured } \\
\text { sand }\left(\mathrm{Kg} / \mathrm{m}^{3}\right)\end{array}$ & $\begin{array}{c}\text { Fly ash } \\
\left(\mathrm{Kg} / \mathrm{m}^{3}\right)\end{array}$ & $\begin{array}{c}\text { Water } \\
\left(\mathrm{Kg} / \mathrm{m}^{3}\right)\end{array}$ & $\begin{array}{c}\mathrm{TH}-2 \\
\left(\mathrm{Kg} / \mathrm{m}^{3}\right)\end{array}$ \\
\hline 0 & 450 & 1000 & 700 & 0 & 110 & 150 & 11.5 \\
30 & 450 & 1000 & 490 & 210 & 110 & 150 & 11.5 \\
50 & 450 & 1000 & 350 & 350 & 110 & 150 & 11.5 \\
70 & 450 & 1000 & 210 & 490 & 110 & 150 & 11.5 \\
100 & 450 & 1000 & 0 & 700 & 110 & 150 & 11.5 \\
\hline
\end{tabular}

\section{Test Method}

Mechanical properties test: the compressive strength, the axis compressive strength, the split strength and the elastic modulus testing against Standard for test mechanical properties on ordinary 
concrete $(G B / T 50081-2002)$. The sizes of test block were $150 \mathrm{~mm} \times 150 \mathrm{~mm} \times 150 \mathrm{~mm}$.

\section{Test Result and Analysis}

The compressive strength of concrete at different ages and replacement ratios were presented in Table 4.

Tab. 4 Compressive strength of concrete (MPa)

\begin{tabular}{cccccccc}
\hline $\begin{array}{c}\text { Replacement } \\
\text { ratio }\end{array}$ & $3 \mathrm{~d}$ & $7 \mathrm{~d}$ & $14 \mathrm{~d}$ & $28 \mathrm{~d}$ & $60 \mathrm{~d}$ & $90 \mathrm{~d}$ & $120 \mathrm{~d}$ \\
\hline $0 \%$ & 37.34 & 47.18 & 52.19 & 61.37 & 67.26 & 73.09 & 79.14 \\
\hline $30 \%$ & 39.30 & 48.77 & 56.84 & 70.05 & 73.82 & 86.04 & 94.11 \\
\hline $50 \%$ & 46.93 & 60.04 & 71.06 & 75.11 & 86.7 & 96.03 & 102.19 \\
\hline $70 \%$ & 48.10 & 60.77 & 69.38 & 72.87 & 84.39 & 92.37 & 97.85 \\
\hline $100 \%$ & 49.75 & 60.74 & 68.31 & 74.39 & 84.52 & 94.05 & 100.51 \\
\hline
\end{tabular}

See Figure 1 and Figure 2 for graphs showing the compressive strength - replacement ratios curve and compressive strength - age curve from Table 4.

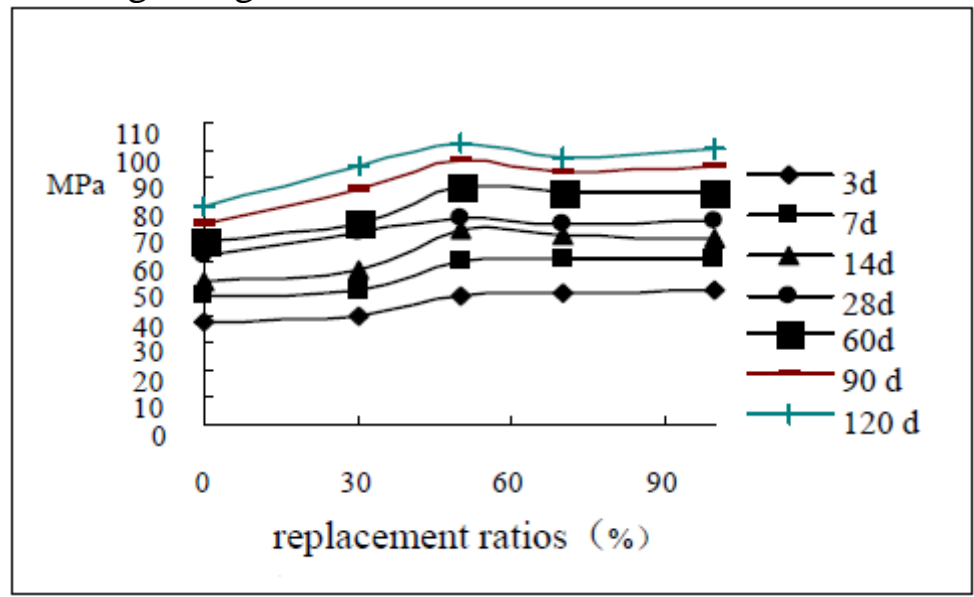

Fig.1 Compressive strength - replacement ratios curve

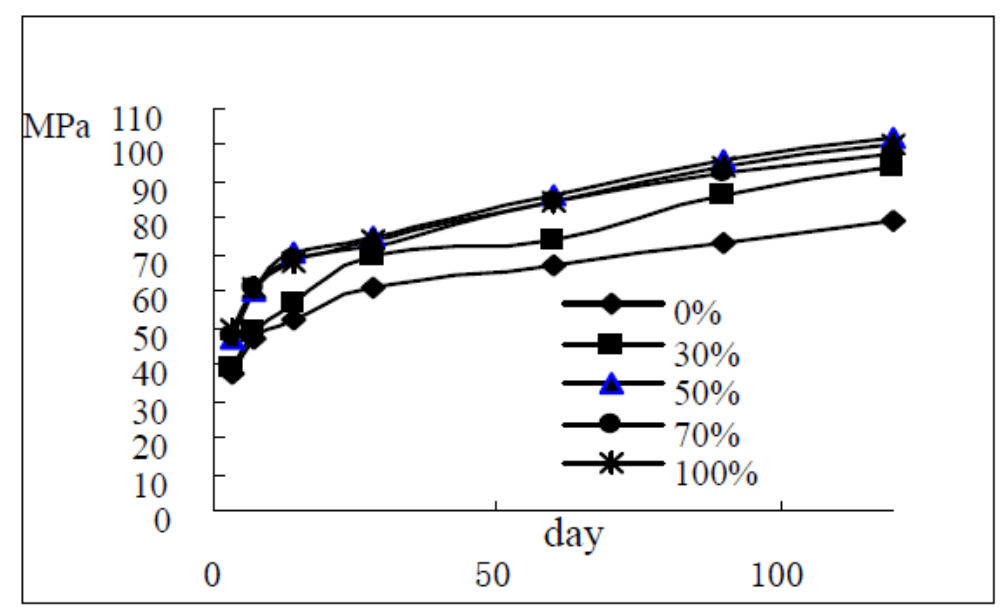

Fig.2 Compressive strength - ages curve

Based on the curves above, three discussions were drawn:

(1)The compressive strength of manufactured sand concrete was greater than natural sand concrete. This was mainly due to manufactured sand improved the interface structure of mastic and aggregate, which increased the density of concrete and the interlocking between aggregates. First, 
the surface of manufactured sand was fresh with rich angular, but there was weathered layer on the surface of natural sand. Second, the mud content of manufactured sand was very low. The low-intensity light material content of manufactured sand was lower, too. Third, the stone dust content of manufactured sand was $4.3 \%$, which filled the gap between the aggregates effectively. This made concrete more compact and improved structural performance. The stone dust could fully decentralize cement powders, and made the hydration of cement adequately, and also played a role of nucleation during cement hydration.

(2)The compressive strength of manufactured sand concrete had the trend of growing with ages increased. After 14 days, the increasing trend of compressive strength got gentle. This might be due to the physical properties of manufactured sand. There were many cracks in the surface of manufactured sand. After 14 days, the destructions of concrete occurred not only on the interface of cement mastic and in cement mastic itself, but also in manufactured sand. So the late strength of manufactured sand concrete grew slower.

(3)The compressive strength of manufactured sand concrete had the trend of growing with the replacement ratio increasing. But after 7 days, the compressive strength of the concrete whose replacement ratio was 50\% was higher than any other concrete in different replacement ratio. The concrete could fully hydrate after 7 days in the condition of this test. This showed that there was an optimum replacement ratio of the manufactured sand by mass to the natural sand. In the range of optimum replacement ratio, concrete had not only good workability but also high compressive strength and durability. This showed that an optimum replacement ratio of the manufactured sand by mass to the natural sand was $50 \%$.

\section{General Conclusion}

The compressive strength of manufactured sand concrete were superior to natural sand concrete in the same circumstances of the water-cement ratio, other materials and admixtures. This showed that it was feasible to produce high properties concrete by using manufactured sand. Through analyzing and comparing the compressive strength of manufactured sand concrete with natural concrete, an optimum replacement ratio of manufactured sand was found. In this test, the optimum replacement ratio of manufactured sand by mass to the natural sand was $50 \%$.

\section{References}

[1] X. Li, Comparative analysis of mechanical properties of concretes mixed with Hubo machine-made and river sand and river sand, J. Shanxi Architecture. 31(2005)112-113.

[2] J.G. Yang, Y.Q Liu, H.C. Yang, Mixing cement mortar and concrete with manufactured sand, J. Railway Construction Technology. 2 (1996)24-31.

[3] J. B Zhang, C. H. Yang, S.C. Fu, Etc. Properties of Concrete Made from Composite Fine Aggregate, J. Journal of Chongqing Jianzhu University. 3(2002)86-90.

[4] D. Zhang, W.G. Liu, H. J. Li, Etc. The Pilot Study of Applications in Manufactured Sand Concrete, J. Shandong Building Materials. 2((2007)65-68.

[5] W. Yi, J. X. Ma, Y. H. Nie, Study on Mechanism of Manufactured Sand Concrete, J. Journal of China \& Foreign Highway.3(2008)151-153.

[6] J.H. Liu, B. Wang, Z. Li, Etc. The Research on the Workability and Compressive Strength of High Performance Concrete Mixed with Machine Sand and Fine Sand, J. Ready-Mixed Concrete. 2(2007)40-42.

[7] X. Li, X. Z. Qin, C.X. Zhang, Machine-made sand and fine sand in high performance concrete, J. Concrete. 12(2004)63-65. 